\title{
KINETICS OF GLICLAZIDE AFTER SINGLE DOSE ORAL ADMINISTRATION OF GLICLAZIDE 60 MG MODIFIED RELEASE TABLET
}

\author{
DIANA IOANA POP,b, ADRIANA MARCOVICI ${ }^{\mathrm{b}}$, MONICA OROIAN ${ }^{\mathrm{a}, \mathrm{b}}$, \\ ANA-MARIA GHELDIU ${ }^{\mathrm{c}, *}$, LAURIAN VLASE ${ }^{\mathrm{a}}$
}

\begin{abstract}
The current study aimed to establish and describe the basic pharmacokinetics of a single dose of gliclazide $60 \mathrm{mg}$ modified release formulation manufactured by Ranbaxy Laboratories Limited, now Sun Pharmaceutical Industries Limited, India. Ten mathematical models were created for analyzing the experimental data resulted from two bioequivalence studies conducted at Clinical Pharmacology and Pharmacokinetics Department of Terapia S.A. Model discrimination was done using the Akaike index value and it was observed that model number 10 (M10) is the model that best describes the gliclazide disposition. This model has two compartments (peripheral and central), mixed order absorption process ( $1^{\text {st }}$ and zero order kinetics) with a lag time of around $3 \mathrm{hrs}$ and $1^{\text {st }}$ order kinetics of elimination. Applying this model in Phoenix software version 6.3 (Pharsight Corp., Mountain view, CA, USA) the main pharmacokinetic parameters of gliclazide were also computed.
\end{abstract}

Keywords: gliclazide, compartmental pharmacokinetic analysis, bioequivalence clinical trials, best model

\section{INTRODUCTION}

Gliclazide, available on market as immediate and modified release formulations, is a second-generation sulphonylurea used as an oral

\footnotetext{
a University of Medicine and Pharmacy 'Iuliu Hațieganu', Faculty of Pharmacy, Department of Pharmaceutical Technology and Biopharmaceutics, 8 Victor Babeș str., RO-400012, ClujNapoca, Romania

b Terapia SA - a Sun Pharma Company, Department of Clinical Pharmacology and Pharmacokinetics, 124 Fabricii str., RO-400632, Cluj-Napoca, Romania

c University of Medicine and Pharmacy 'Iuliu Hațieganu', Faculty of Pharmacy, Department of Pharmaceutical Botany, 23 Marinescu str., RO-400337, Cluj-Napoca, Romania

*Corresponding author: anamaria.gheldiu@yahoo.com
} 
hypoglycaemic agent for the treatment of type 2 diabetes (T2DM) $[1,2,3]$. Gliclazide is part of the World Health Organization (WHO) list with essential drugs and it was first used in 1972, thus having a long history of clinical use and several generics available on the market $[4,5,6]$.

Gliclazide is chemically known as $1-(3,3 \mathrm{a}, 4,5,6,6 \mathrm{a}-$ hexahydro- $1 \mathrm{H}-$ cyclopenta[c] pyrrol-2-yl)-3-(4-methylphenyl)sulfonylurea (IUPAC name) (see Figure 1).

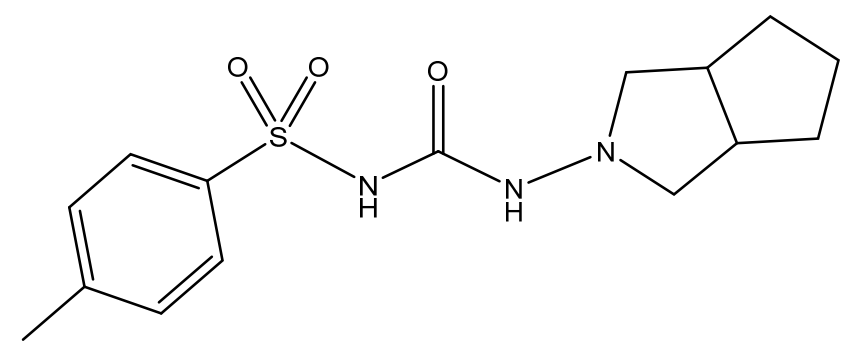

Figure 1. Chemical structure of gliclazide

It is different from other sulphonylureas as it has an $\mathrm{N}$-containing heterocyclic ring and an endocyclic bond. It has a molecular weight of 323.4 $\mathrm{g} / \mathrm{mol}$ and the molecular formula $\mathrm{C}_{15} \mathrm{H}_{21} \mathrm{~N}_{3} \mathrm{O}_{3} \mathrm{~S}[7,8,9]$.

The levels of blood glucose are reduced by gliclazide as it stimulates the insulin secretion of pancreatic islets $\beta$-cells. It binds to sulfonylurea receptors available on the surface of pancreatic beta cells (SUR-1) selectively, inducing insulin release. It shows a good safety profile and ensures cardiovascular protection, as gliclazide has no affinity for sulfonylurea receptors in the heart (SUR-2A) $[7,9,10,11,12]$. Moreover, gliclazide presents extra-pancreatic effects and hemovascular properties $[7,13,14]$.

The main organ for gliclazide's metabolization is the liver. In plasma were not found any active metabolites. In urine were detected at least eight metabolites. The major metabolic pathway of gliclazide metabolization involves the tolylmethyl hydroxylation and then oxidation to the corresponding carboxylic acid. Seven monohydroxylated metabolites could be obtained after the hydroxylation of the azabicyclo-octyl moiety. Transporters were not proved to be involved in gliclazide's disposition $[15,16,17]$. 
The main role in gliclazide metabolic clearance is attributed to cytochrome P450 2C9 (CYP2C9) and possibly CYP2C19 and CYP2C18. CYP2C9 polymorphism and other pharmacodynamic factors could explain the gliclazide individual differences that have been reported [16,18, 19,20,21].

The pharmacokinetics describes how a drug is disposed in the human body and studies the processes like absorption, distribution, metabolism and excretion (ADME), processes that occur in time after drug administration. It analyses the relationship between the pharmacological effect that is exerted by the active substance and the administered drug dose and gives a deep insight into the mechanisms that are involved in the physiologic process that a drug undergoes in the body [22,23,24].

Using the pharmacokinetic compartmental analysis the ADME processes can be characterized by establishing the pharmacokinetic (PK) parameters. Individualized therapy or specific dose-adjustment for patients could be determined considering the PK profile of the drug. In addition, the PK parameters and the drug profile are very useful for the formulations that undergo bioequivalence studies for approval of generic products [22,23,24]

Therefore, it is essential that the disposition in the human body and the basic PK model of gliclazide should be described before the approval of a new generic $60 \mathrm{mg}$ modified release tablet.

The aim of the presented study was to establish and describe the best PK model that accurately reflects the kinetics processes of ADME processes for gliclazide, after a single $60 \mathrm{mg}$ oral dose in healthy Caucasian volunteers of the newly developed modified release formulation. The predicted values were compared with the actual experimental data that resulted from two bioequivalence studies conducted under fasting and fed conditions at the Clinical Pharmacology and Pharmacokinetics Department of Terapia S.A.

\section{RESULTS AND DISCUSSION}

Ten mathematical models were created with the purpose of analyzing the PK profile of gliclazide and are given in Table 1.

The differences between the ten PK models consisted in different assumptions about the absorption kinetics of gliclazide, number of compartments for the drug, and existence of lag time from the time of drug administration until the beginning of drug absorption. The corresponding mathematical differential equations were written and run for each PK model with Phoenix 6.3 software package (Pharsight Corp., Mountain view, CA, USA). 
DIANA IOANA POP, ADRIANA MARCOVICI, MONICA OROIAN, ANA-MARIA GHELDIU, LAURIAN VLASE

Table 1. Pharmacokinetic models of gliclazide used in compartmental analysis

\begin{tabular}{|c|c|c|c|}
\hline $\begin{array}{c}\text { Pharmacokinetic } \\
\text { model }\end{array}$ & $\begin{array}{l}\text { Absorption } \\
\text { kinetics }\end{array}$ & Lag time & $\begin{array}{c}\text { Number of } \\
\text { compartment }\end{array}$ \\
\hline $\mathrm{M} 1$ & $1^{\text {st }}$ order & No & 1 \\
\hline M2 & $1^{\text {st }}$ order & Yes & 1 \\
\hline M3 & Zero order & No & 1 \\
\hline M4 & Zero order & Yes & 1 \\
\hline M5 & $1^{\text {st }}$ order & No & 2 \\
\hline M6 & $1^{\text {st }}$ order & Yes & 2 \\
\hline M7 & Zero order & No & 2 \\
\hline M8 & Zero order & Yes & 2 \\
\hline M9 & $\begin{array}{l}1^{\text {st }} \text { order and } \\
\text { zero order }\end{array}$ & Yes & 1 \\
\hline M10 & $\begin{array}{l}1^{\text {st }} \text { order and } \\
\text { zero order }\end{array}$ & Yes & 2 \\
\hline
\end{tabular}

The PK scheme for model 10 (M10) is shown in Figure 2.

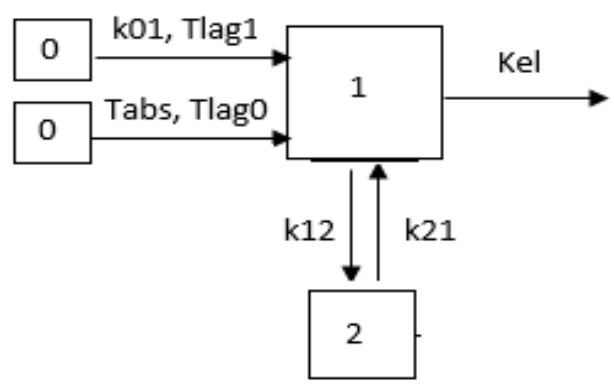

Figure 2. Schematic representation of kinetic processes for model M10, where " 0 " are absorption compartments of gliclazide; " 1 " is the central compartment of gliclazide; " 2 " is gliclazide peripheral compartment; $T_{\text {lago }}$ and $T_{\text {lag1 }}$ are the latency times for absorption; Tabs is the time needed for zero order absorption and $\mathrm{k}_{01}$ is the $1^{\text {st }}$ order absorption rate constants of gliclazide; $k_{12}$ and $k_{21}$ are the distribution rate constants for gliclazide; $\mathrm{K}_{\mathrm{el}}$ is the elimination rate constant for gliclazide

The mean plasma concentrations of gliclazide were analysed using the ten kinetic models described, after they were implemented in Phoenix software. The same settings of minimisation engine was used for the evaluated models: weighting scheme was 1/y (1/observed concentration), minimisation method was Gauss-Newton (Levenberg and Hartley variant), and convergence criterion was 0.0001 . 
The Akaike index value (AIC) was automatically calculated for each PK model and further used for model discrimination, considering that a smaller value of this index would be attributed to the model that best fits the experimental data $[23,24]$. The Akaike values for the ten PK models that were evaluated for the study under fasting condition are given in Figure 3, while the Akaike values for PK models assessed for the study under fed condition are shown in Figure 4.

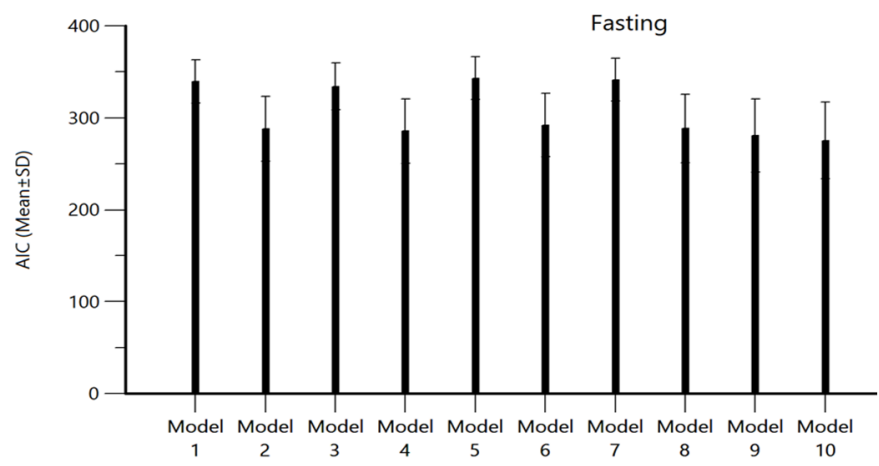

Figure 3. Akaike index values for mathematical evaluated for characterisation of gliclazide disposition in the body, after administration of a single dose 60 mg modified release tablet in subjects under fasting condition

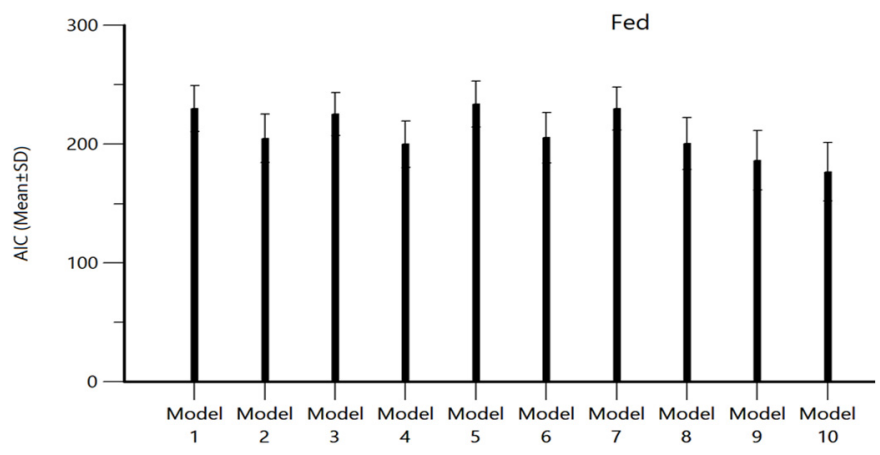

Figure 4. Akaike index values for mathematical evaluated for characterisation of gliclazide disposition in the body, after administration of a single dose 60 $\mathrm{mg}$ modified release tablet in subjects under fed condition

In Figure 5 are presented typical fitting of four data sets for subjects from the bioequivalence fasting study, while in Figure 6 are illustrated other four typical fitting of data sets from subjects who participated in the bioequivalence fed study. The best model to describe gliclazide disposition was M10, with the lowest AIC value. 
DIANA IOANA POP, ADRIANA MARCOVICI, MONICA OROIAN, ANA-MARIA GHELDIU, LAURIAN VLASE
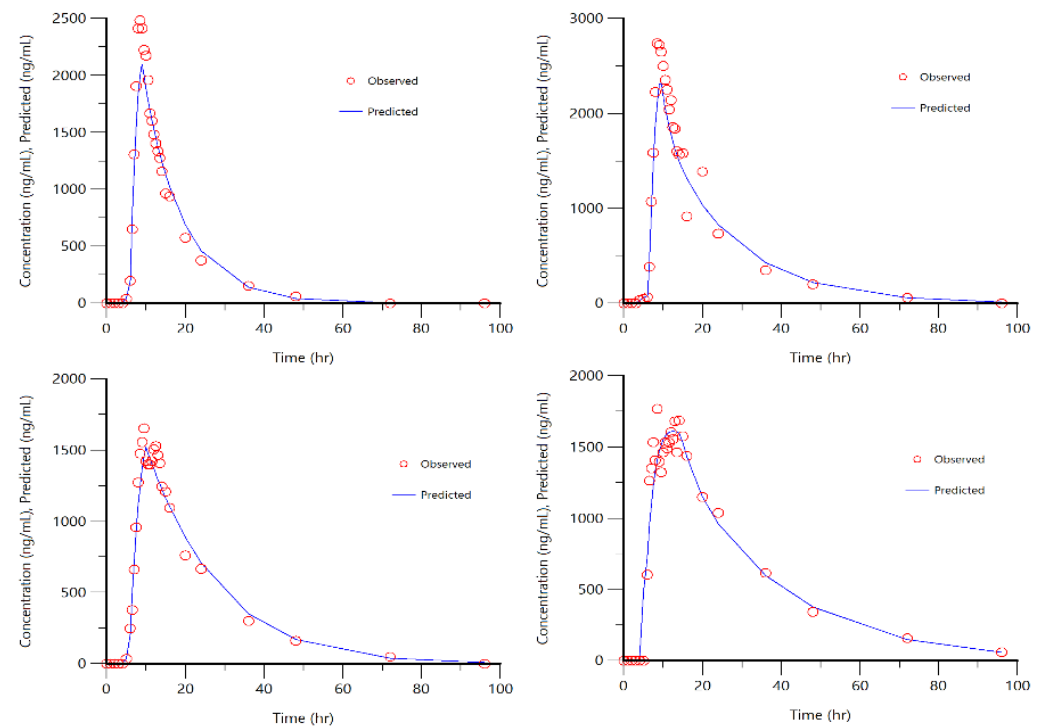

Figure 5. Typical fitting of model M10 for four data sets of experimentally determined plasma concentrations of gliclazide (data from clinical trial under fasting condition)
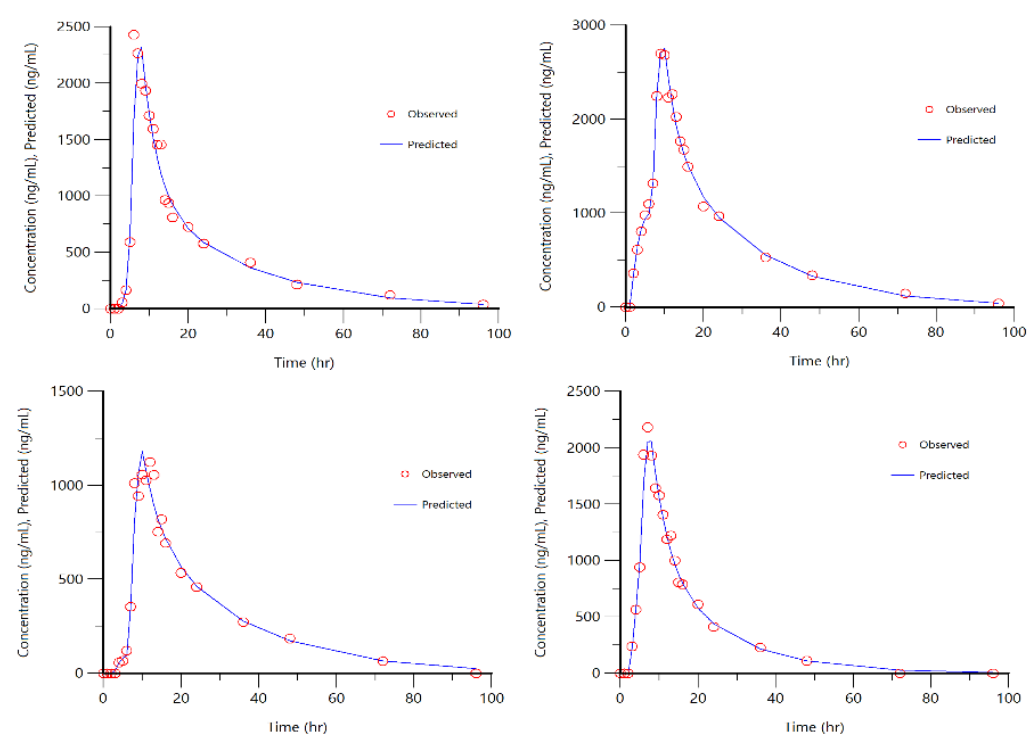

Figure 6. Typical fitting of model M10 for four data sets of experimentally determined plasma concentrations of gliclazide (data from clinical trial under fed condition) 
After applying the representative kinetic model for gliclazide (M10) in Phoenix software for fitting all data sets, its characteristic individual PK parameters were computed, for both studies (fasted and fed). In Table 2 are shown the mean PK parameters for fasting study and fed study, side-by-side.

Table 2. The mean pharmacokinetic parameters of gliclazide calculated with M10, for fasting and fed study

\begin{tabular}{|c|c|c|c|c|c|c|}
\hline \multirow{3}{*}{$\begin{array}{l}\text { PK parameter } \\
\text { (units) }\end{array}$} & \multicolumn{6}{|c|}{ Food } \\
\hline & \multicolumn{3}{|c|}{ Fasting } & \multicolumn{3}{|c|}{ Fed } \\
\hline & Mean & SD & CV\% & Mean & SD & CV\% \\
\hline $\mathbf{f}$ & 0.20 & 0.14 & 71.55 & 0.15 & 0.11 & 72.35 \\
\hline $\mathrm{T}_{\text {lag1 }}(\mathrm{hr})$ & 2.96 & 1.04 & 34.99 & 2.85 & 0.84 & 29.51 \\
\hline $\mathrm{K}_{1}\left(\mathrm{hr}^{-1}\right)$ & 0.48 & 0.53 & 109.95 & 0.44 & 0.30 & 67.45 \\
\hline $\mathrm{T}_{\text {lago }}(\mathrm{hr})$ & 5.51 & 0.93 & 16.91 & 5.53 & 0.84 & 15.21 \\
\hline $\mathrm{T}_{\text {abs }}(\mathrm{hr})$ & 4.21 & 1.91 & 45.36 & 3.72 & 1.44 & 38.70 \\
\hline $\mathrm{K}_{12}\left(\mathrm{hr}^{-1}\right)$ & 0.07 & 0.05 & 71.64 & 0.06 & 0.04 & 61.20 \\
\hline $\mathrm{K}_{21}\left(\mathrm{hr}^{-1}\right)$ & 0.40 & 0.27 & 69.00 & 0.19 & 0.18 & 91.96 \\
\hline $\mathrm{K}_{\mathrm{el}}\left(\mathrm{hr}^{-1}\right)$ & 0.07 & 0.02 & 31.77 & 0.07 & 0.02 & 32.35 \\
\hline$V_{d_{-}} F(L)$ & 17.21 & 7.40 & 43.03 & 18.44 & 5.28 & 28.66 \\
\hline
\end{tabular}

${ }^{*} f$ - fraction of dose absorbed following first order kinetics.

By evaluating Figures 3 and 4, it can be observed that model M10 fits the experimental data better than its concurrent models, having the smallest AIC value. Thus, it was selected as representative for gliclazide disposition after single dose oral administration. According to M10, the pharmacokinetics of gliclazide is characterised by a mixed absorption kinetics, $1^{\text {st }}$ order and zero order kinetics, and bicompartmental distribution. Gliclazide is further eliminated from the body following a $1^{\text {st }}$ order kinetics.

The obtained data revealed the importance of the latency time of absorption ( $T_{\text {lag }}$ was approximately $3 \mathrm{hrs}$ ), which is consistent with the fact that gliclazide was administered as a single dose modified release tablet. This is supported by lower AIC values for models that considered lag time. The latency time could be attributed, in addition, to gastric emptying time or to lesser extent, to food intake. It was noticed an insignificant difference between latency time of absorption under fasting versus fed condition $(2.96 \pm 1.04 \mathrm{hr}$ versus $2.85 \pm 0.84$ $\mathrm{hr}$ ), which implies no significant food effect on the $\mathrm{T}_{\text {lag }}$ of absorption [25].

On the other hand, unitary absorption kinetics was found to be not relevant for the data, neither in fasting study nor in fed study, fact highlighted by the significantly higher AIC values for the models that considered that absorption process follows a single order kinetics. Hence, two new complex 
models were created and evaluated, namely M9 and M10, which assumed that gliclazide is subjected to a mixed order absorption of $1^{\text {st }}$ and zero order. Based on the AIC value, it was concluded that M10 is the best model for describing the gliclazide disposition.

The dose fraction (f) that is absorbed following a $1^{\text {st }}$ order kinetics was higher in the case of fasting than fed condition ( $20 \%$ vs $15 \%$, see Table 2$)$, the rest of the dose being absorbed by zero order kinetics.

\section{CONCLUSIONS}

The basic PK model for gliclazide that best describes its disposition in the body was determined and characterized. It consists of two compartments, a central and a peripheral compartment, a mixed order absorption ( $1^{\text {st }}$ order and zero order kinetics), and a lag time of approximately $3 \mathrm{hrs}$ for the onset of absorption process after drug administration.

\section{EXPERIMENTAL SECTION}

Subjects: The clinical study data (plasma concentration versus time profile) were obtained from two bioequivalence trials that were conducted at the Clinical Unit of Clinical Pharmacology and Pharmacokinetics Department of Terapia S.A. 41 Caucasian healthy volunteers completed the first bioequivalence study conducted under fasting state, while 23 volunteers finalized the second bioequivalence study, carried out under fed state of subjects. The eligibility of the volunteers for both clinical studies was assessed based on their medical records, on-site physical examination, vital signs, and clinical laboratory tests results. The study protocols were approved by the Ethics Committee of the University of Medicine and Pharmacy "Iuliu Hatieganu", from Cluj-Napoca (Romania) and by the National Agency for Medicines and Medical Devices, Romania [26,27]. The clinical trials were conducted in accordance with all applicable regulatory requirements. All volunteers signed the written informed consent before initiation of any study procedure.

Study design: Each bioequivalence study was designed as an openlabel, randomized, single-dose, crossover study that consisted of two periods during which the subjects were given the test product developed by Ranbaxy Laboratories Limited, now Sun Pharmaceutical Industries Limited, India, and the reference product Diamicron ${ }^{\circledR}$ MR, Servier, France $[26,27]$.

Drug administration: For the fasting study the subjects were required to have a fasting period of at least 10 hours before administration of the investigational products. For the fed study after a 10 hours fasting period, all 
subjects were given a standard meal (high-fat, high-calorie) with 30 minutes before drug administration. The investigational products were administered with $240 \mathrm{~mL}$ of $20 \%$ glucose solution [26,27].

Sample collection: The blood samples of $4 \mathrm{~mL}$ each were collected in $\mathrm{K}_{3}$ EDTA vacutainers prior to drug administration and up to 96 hours postdose in each bioequivalence study. The samples were centrifuged, plasma was separated and stored at $-50^{\circ} \mathrm{C}$ until analysis [26,27].

Drug analysis from plasma samples: The plasma concentrations of gliclazide were obtained by using the validated high-throughput liquid chromatography-tandem mass spectrometry (LC-MS/MS) using Gliclazide D4 as internal standard. The limit of quantification was $5.00 \mathrm{ng} / \mathrm{mL}$, required plasma volume of $150 \mu \mathrm{L}$ and a run time of approximately $(2.5 \mathrm{~min})$ [26,27].

Pharmacokinetic and statistical analysis: For both bioequivalence clinical trials, the pharmacokinetic analysis (noncompartmental) was performed with WinNonlin ${ }^{\circledR} P K$ software version 5.2 and the main $P K$ parameters $C_{\max }, T_{\max }$, $A \cup C_{0-t}, A C_{0-\infty}, A U C \%$ Extrap and $T_{1 / 2}$ were calculated. Statistical analysis was performed with SAS software version 9.1.3 for log-transformed $C_{\max }, A U_{0-t}$ and $\mathrm{AUC}_{0-\infty}$ using ANOVA. Ratios of means and the $90 \%$ confidence intervals were calculated and the obtained values were between $80 \%$ and $125 \%$. For the analysis of gliclazide's disposition in the body, the compartmental analysis module of WinNonlin ${ }^{\circledR}$ PK software version 5.2 was used. [26,27].

\section{ACKNOWLEDGMENTS}

Financial disclosures: Ana-Maria Gheldiu and Laurian Vlase are full-time employees of the University of Medicine and Pharmacy "Iuliu Hatieganu", Cluj-Napoca, Romania.

Conflicts of interest: Diana Pop, Adriana Marcovici and Monica Oroian were employees of the Ranbaxy Laboratories Limited, now Sun Pharmaceutical Industries, India, during the conduct of this study.

\section{REFERENCES}

1. Z.X. He; Z.-W. Zhou; Y. Yang; T. Yang; S.-Y. Pan; J.-X. Qiu; S.-F. Zhou; Clin. Exp. Pharmacol P., 2015, 42, 125-138

2. M. Alsharidah; M. Algeffari; H. Abdel-Moneim; M.F. Lutfi; H. Alshelowi; Saudi Pharm. J., 2018, 26, 1-6

3. G.W.D. Landman; G.H. de Bock; K.J.J. van Hateren; P.R. van Dijk; K.H. Groenier; R.O.B. Gans; S.T. Houweling; H.J.G. Bilo; N. Kleefstra; PLoS ONE., 2014, 9, article number e82880 
4. C.J. Bailey; A.J. Krentz; Oral Antidiabetic Agents. In Textbook of Diabetes, $4^{\text {th }}$ ed.; R.I. G. Holt, C.S. Cockram, A. Flyvbjerg, B.J. Goldstein Eds.; WileyBlackwell, Oxford, UK, 2010, Part 6 - Chapter 29, pp. 452-477

5. S. Colagiuri; D. Matthews; L.A. Leiter; S.P. Chan; G. Sesti; M. Marre; Diabetes Res. Clin. Pract., 2018, 143, 1-14

6. D.I. Pop; A. Marcovici; M. Oroian; A.-M. Gheldiu; L. Vlase; Studia UBB Chemia, 2019, LXIV, 217-229

7. O. Ziegler; P. Drouin; Diabetes Res. Clin. Pract., 1991, 14, S83-S89

8. M.S. Arayne; N. Sultana; M.K. Zaman; Pak. J. Pharm. Sci., 2003, 16, 35-49

9. A. Sarkar; A. Tiwari; P.S. Bhasin; M. Mitra; J. Appl. Pharm. Sci., 2011, 01, 11-19

10. H. de Wet; P. Proks; Biochem. Soc. Trans., 2015, 43, 901-907

11. G. Müller; Y. Satoh; K. Geisen; Diabetes Res. Clin. Pract., 1995, 28, S115-S137

12. C.L. Lawrence; P. Proks; G.C. Rodrigo; P. Jones; Y. Hayabuchi; N.B. Standen; F.M. Ashcroft; Diabetologia, 2001, 44, 1019-1025

13. P.E. Jennings; Metabolism, 2000, 49, 17-20

14. S. Zoungas; J. Chalmers; A.P. Kengne; A. Pillai; L. Billot; B. de Galan; M. Marre; B. Neal; S. Harrap; N. Poulter; A. Patel; Diabetes Res. Clin. Pract., 2010, 89, 126-133

15. N. Rojanasthien; T. Autsavakitipong; B. Kumsorn; M. Manorot; S. Teekachunhatean; ISRN Pharmacol., 2012, 2012, article ID 375134

16. H. Xu; K.M. Williams; W.S. Liauw; M. Murray; R.O. Day; A.J. McLachlan; Br. J. Pharmacol., 2008, 153, 1579-1586

17. T.M.E. Davis; F. Daly; J.P. Walsh; K.F. Ilett; J.P. Beilby; L.J. Dusci; P.H.R. Barrett; Br. J. Clin. Pharmacol., 2000, 49, 223-230

18. D.J. Elliot; H.N. Suharjono; B.C. Lewis; E.M.J. Gillam; D.J. Birkett; A.S. Gross; J.O. Miners; Br. J. Clin. Pharmacol., 2007, 64, 450-457

19. W. Zeng; Y. Guo; P. Chen; Z. Liu; D. Chen; C. Han; J. Diabetes Investig., 2016, 7, 764-768

20. F. Yang; X. Xiong; Y. Liu; H. Zhang; S. Huang; Y. Xiong; X. Hu; C. Xia; Sci. Rep., 2018, 8, article number 10994

21. Y. Yao; W.W. Han; Y.H. Zhou; Z.S. Li; Q. Li; X.Y. Chen; D.F. Zhong; Eur. J. Med. Chem., 2009, 44, 854-861

22. M. Oroian; A. Marcovici; D.I. Pop; S. Bhardwaj; A. Khuroo; A.-M. Gheldiu; L. Vlase; Studia UBB Chemia, 2019, LXIV, 297-308

23. A.-M. Gheldiu; A. Csavdari; M. Achim; L. Vlase; I. Tomuta; D.M. Muntean; Studia UBB Chemia, 2017, LXII, 179-188

24. A.-M. Gheldiu; D.M. Muntean; I. Cristea; I. Antonescu; R. Chira; C. Ureche; L. Vlase; Rev. Chim. (Bucharest), 2016, 67, 702-705

25. D.I. Pop; A.-M. Gheldiu; M. Oroian; A. Marcovici; S. Bhardwaj; A. Khuroo; R. Kochhar; L. Vlase; Acta Med. Marisiensis, 2018, 64, 161-168

26. D.I. Pop; M. Oroian; S. Bhardwaj; A. Marcovici; A. Khuroo; R. Kochhar; L. Vlase; Clin. Pharm. Drug Dev., 2019, 8, 16-21

27. D.I. Pop; M. Oroian; S. Bhardwaj; A. Marcovici; A. Khuroo; R. Kochhar; L. Vlase; Farmacia, 2018, 66, 597-601 